\title{
Compact Tri-Band Notched Characteristics UWB Antenna for WiMAX, WLAN and X-Band Applications
}

\author{
Ehab K. I. Hamad ${ }^{1}$ and Nirmen Mahmoud ${ }^{2}$ \\ Electrical Engineering Department, Faculty of Engineering, Aswan University, Aswan 81542, Egypt \\ *corresponding author, E-mail: e. hamadeaswu .edu.eg
}

\begin{abstract}
Compact microstrip-fed printed monopole antenna with triple band-notched characteristics is suggested for ultra wideband (UWB) applications. The antenna is constructed of a conventional rectangular microstrip patch antenna with partial ground plane and T-shaped strip employed in the ground plane as well as an inverted $\Omega$ - and L-shaped slots incorporated within the radiated element. The notched functions are created by the inverted $\Omega$ - and L-shaped slots, which are realized for WiMAX (from 2.69 to $4.5 \mathrm{GHz}$ ) and WLAN (from 5.49 to $6.37 \mathrm{GHz}$ ). The T-shaped parasitic strip generates the third notch for the X-band uplink satellite communication (from 8.15 to $9.61 \mathrm{GHz}$ ). The measured operating $-10 \mathrm{~dB}$ bandwidth of the proposed antenna extends from 2.39 to more than $18 \mathrm{GHz}$ except at the notched bands. The prototype antenna has a total area of $20 \times 20 \times 1.6$ $\mathrm{mm}^{3}$. The EM simulations are carried out using 3D fullwave FEM-based simulator; the Ansoft High Frequency Structure Simulator (HFSS). EM simulation results are in good agreement with measurement results. The radiation pattern of the proposed antenna is nearly Omni-directional over the whole band.
\end{abstract}

\section{Introduction}

Ultra wide band (UWB) communication systems have attractive a prodigious attention in last two decades particularly when the Federal Communication Commission (FCC) has assigned the unlicensed radio spectrum from $3.1 \mathrm{GHz}$ to 10.6 GHz in February 2002 for commercial UWB communication applications [1]. Due to advantages of UWB technology such as enormously low power spectral density, low profile, high radiation efficiency, high speed data transmission, low cost and wide bandwidth; a lot of researches in both industry and academic pertaining to UWB systems have occurred. The challenges of the execution of UWB systems are the growth of a suitable antenna that has a wide impedance bandwidth and an omnidirectional radiation pattern over the entire frequency range [2-4]. Printed monopole antennas are the most frequently used antennas for UWB applications because they are more popular due to their easier integration with monolithic microwave integrated circuits (MMICs), small size and low profile $[5,6]$. To avoid interference with other existing narrowband applications that inhabits part of the spectrum in the UWB band [7], such as World Wide Interoperability Microwave Access (WiMAX) in the 3.3-3.6
GHz band, Wireless Local Area Network (WLAN) in the 5.15-5.825 GHz band, X-band satellite communication systems in the 7.25-8.4 GHz band, WiFi in the $5.47 \mathrm{GHz}-5.725$ $\mathrm{GHz}$ band and C-band in the 3.7-4.2GHz band; a band stop filter (BSF) is integrated into the antenna but these action increases the complexity, volume and cost of the system [8]. To overcome the problem of using BSF to avoid the interface of the narrowband applications within the UWB band; it is desirable to design UWB antennas with band-notched characteristics; this can be attained by different methods. The conventional methods to achieve band-notched function are by etching different shapes of slots in the radiating patch or in the ground plane [9-13], or by using parasitic elements in the aperture area of the antenna $[14,15]$ or by embedding a slit in the feed line that leads to a sudden change in the impedance in the notched band $[16,17]$.

An ultra-wide band antenna with dual band-notched characteristics with an impedance bandwidth from 2 to $13.7 \mathrm{GHz}$ and $50 \times 40 \mathrm{~mm}^{2}$ size, and U-shaped defected patch structure as well as $\Pi$-shaped defected patch structure are applied to obtain a dual band-notched characteristics covering WiFi and WiMAX, are presented in [18]. The authors have designed in [19] a planer CPW fed UWB monopole antenna with triple band notch characteristics with dimension of $45 \times 41 \mathrm{~mm}^{2}$, U-shaped slot is etched out from the radiator, which attains a notched band centered at $3.5 \mathrm{GHz}$ and 10.5 $\mathrm{GHz}$ and, a band notch centered at $5.5 \mathrm{GHz}$ is obtained using L-shaped slots etched in the ground plane; the impedance bandwidth covers the frequency range from $2.8 \mathrm{GHz}$ to 12 GHz. In [20] a compact triple band-notched UWB printed monopole antenna with two round shaped slots inserted in radiating patch and, a pair of $\mathrm{C}$-shaped slots etched in the ground plane is proposed with frequency range from 3 to $15 \mathrm{GHz}$, the designed antenna has a size of $31 \times 22 \mathrm{~mm}^{2}$. Printed plaque monopole antenna fed by a microstrip line for UWB with triple notch band have been suggested in literature [21], the design antenna (of size $30 \times 30 \mathrm{~mm}^{2}$ ) is modified to retain band rejection at the wireless local area network using an inverted U-shape slot or $\Pi$-shape slot, or $\Lambda_{-}$ shape slot within the radiating patch; two U-slots are cuts in the radiating patch to generate the first and third notch band in $3.25-3.75 \mathrm{GHz}$ for WiMAX and 7.25-7.75 GHz for down link of X-band satellite communication system. An UWB printed monopole antenna with triple bands notched operates from 2.9 to $10.9 \mathrm{GHz}$ with an overall size of $27 \times 25 \mathrm{~mm}^{2}$ is proposed in [10]; by etching two round shape slots in the radiating patch and a pair of rotated V-shape slot are etched 
on the ground plane, the notched characteristics are achieved.

In this paper; a compact printed monopole UWB antenna with triple band-notched characteristics is presented. The proposed antenna is printed on the cheap FR4 substrate of 4.4 relative permittivity and $1.6 \mathrm{~mm}$ thickness with total area of $20 \times 20 \mathrm{~mm}^{2}$. A bandwidth of 2.39 up to $18 \mathrm{GHz}$ is accomplished. The Tri-band notched characteristics are acquired by etching an L-shape and inverted $\Omega$-shape slots within the radiating patch and a $\mathrm{T}$-shaped parasitic strip is incorporated in the ground plane.

\section{Antenna Design}

The schematic diagram of the proposed antenna is demonstrated in Fig. 1. This antenna is printed on a cheap FR4 substrate with a thickness of $1.6 \mathrm{~mm}$, relative permittivity $\varepsilon_{r}$ $=4.4$, and loss tangent, $\tan \delta=0.02$. The proposed antenna size is $20 \times 20 \times 1.6 \mathrm{~mm}^{3}$. The antenna comprises of a $50 \Omega$ microstrip feed line with $2 \mathrm{~mm}$ width and $5 \mathrm{~mm}$ height, and a planar radiating rectangular patch printed on the top side of the dielectric substrate and a finite ground plane of length $L_{\mathrm{g}}=3 \mathrm{~mm}$ on the back side of the substrate. By means of a 3D full-wave Finite Element Method-based, Ansoft High Frequency Structure Simulator (HFSS), the antenna performance has been designed and optimized. The final optimized dimensions of the proposed antenna are listed in Table 1.

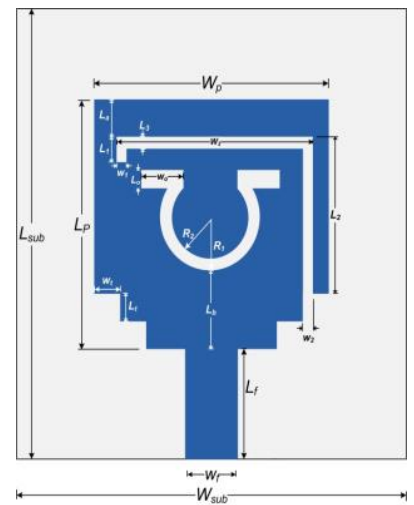

Front view

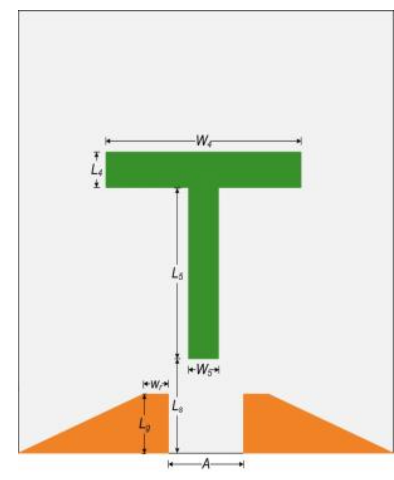

Back view
Figure1: Schematic diagram of the proposed antenna.

The antenna design procedure starts by designing a conventional rectangular patch antenna with full ground plane, and then the ground plane is removed partially to satisfy the UWB characteristics. To enhance the impedance bandwidth, different slots are cut from the lower edge of the radiated element in stepped manner, while a trapezoidal cut in the ground plane is performed. To understand the influence of the staircases cuts within the patch and the trapezoidal cut within the ground plane, the return loss of the proposed antenna is compared with the return loss of the conventional microstrip patch antenna with full metallic ground in Fig. 2.
Table 1: Optimal design parameters of the final design (all values in $\mathrm{mm}$ )

\begin{tabular}{cc|cc|cc|cc}
\hline $\begin{array}{c}\text { Pa- } \\
\text { rame } \\
\text { ter }\end{array}$ & $\begin{array}{c}\text { Val- } \\
\text { ue }\end{array}$ & $\begin{array}{l}\text { Param- } \\
\text { eter }\end{array}$ & $\begin{array}{c}\text { Val- } \\
\text { ue }\end{array}$ & $\begin{array}{c}\text { Param- } \\
\text { eter }\end{array}$ & $\begin{array}{c}\text { Val- } \\
\text { ue }\end{array}$ & $\begin{array}{c}\text { Param- } \\
\text { eter }\end{array}$ & $\begin{array}{c}\text { Val- } \\
\text { ue }\end{array}$ \\
\hline$W_{\text {sub }}$ & 20 & $h$ & 1.6 & $W_{t}$ & 2 & $W_{l}$ & 0.5 \\
$L_{s u b}$ & 20 & $A$ & 3 & $L_{t}$ & 1 & $W_{2}$ & 0.5 \\
$W_{g}$ & 20 & $W_{r}$ & 5.5 & $L_{o}$ & 1 & $W_{3}$ & 9 \\
$L_{g}$ & 3 & $W_{4}$ & 9 & $W_{o}$ & 1.95 & $L_{l}$ & 1 \\
$W_{f}$ & 2 & $L_{4}$ & 1 & $L_{a}$ & 2 & $L_{2}$ & 6.5 \\
$L_{f}$ & 5 & $W_{5}$ & 1 & $L_{b}$ & 5.5 & $L_{3}$ & 0.5 \\
$W_{p}$ & 10 & $L_{5}$ & 7 & $R_{I}$ & 2 & & \\
$L_{p}$ & 10 & $L_{s}$ & 4 & $R_{2}$ & 1.5 & & \\
\hline
\end{tabular}

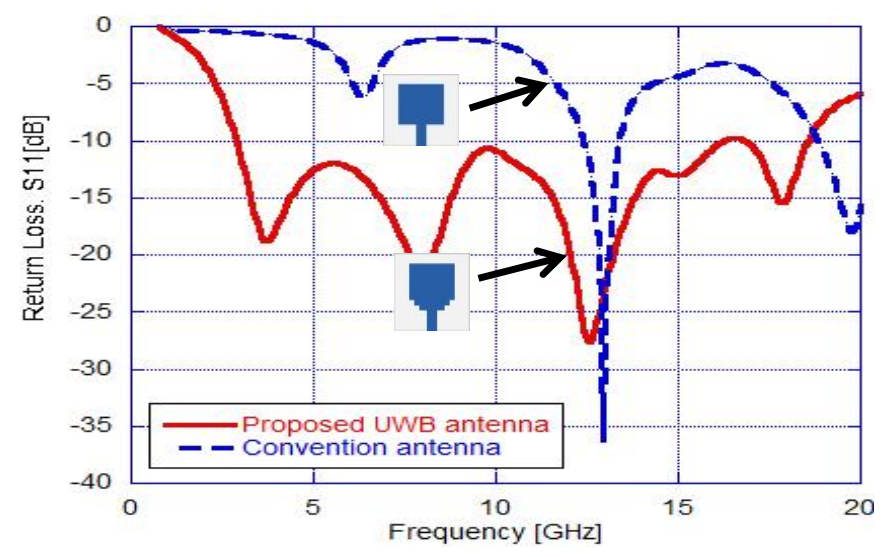

Figure 2: The proposed antenna versus conventional one.

\section{Parametric Results}

A parametric study of the antenna's parameters in this section is conducted in order to find out the inspiration of some major parameters on the antenna performance in addition to the notched characteristics of the antenna.

\subsection{Effect of the Width of the Trapezoidal Cut in the Ground Plane $\left(W_{\mathbf{r}}\right)$}

Figure 3 displays the simulated returns loss for different values of $W_{\mathrm{r}}$. The response illustrates that as the value of $W_{\mathrm{r}}$ is selected greater than $5.5 \mathrm{~mm}$ the bandwidth become narrower.

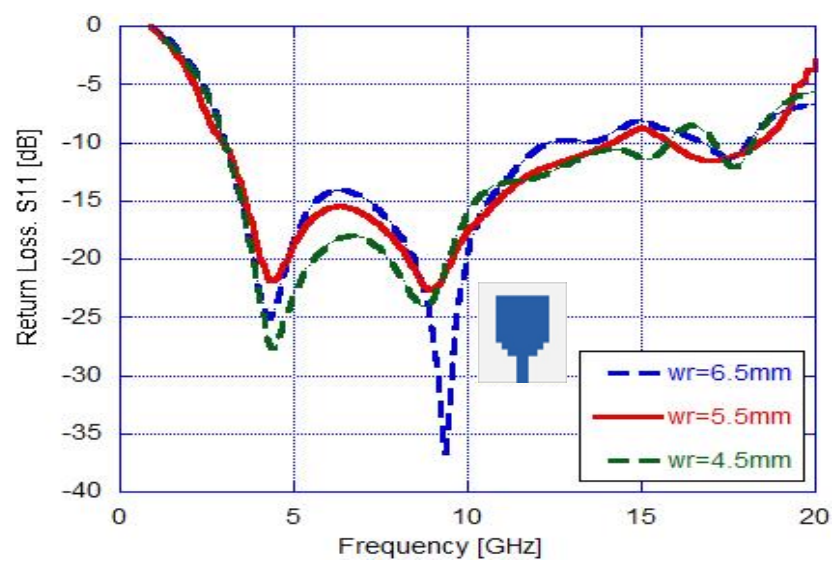

Fig. 3 Simulated return loss, $S_{11}$ for different $W_{\mathrm{r}}$ values. 


\subsection{Effect of the Ground Height $\left(L_{\mathrm{g}}\right)$}

This parameter is mainly controls the impedance bandwidth of the antenna. As shown in Fig. 4, the returns loss, $S_{11}$ for several values of $L_{\mathrm{g}}$ is being investigated to get the optimal value for the partial ground plane width, which is achieved to be about $3 \mathrm{~mm}$.

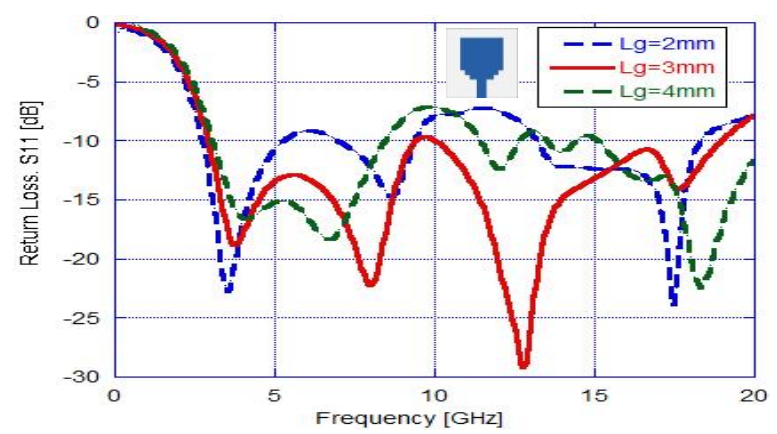

Figure 4: Simulated return loss, $S_{11}$ for various ground height $L_{\mathrm{g}}$ values.

A rectangular cut within the partial ground plane underneath the feed line with total width (A) of $3 \mathrm{~mm}$ is employed to much improve the impedance bandwidth.

\section{First Notched Band}

To achieve the desired band notched characteristics at 5.5 $\mathrm{GHz}$ center frequency for WLAN applications, a T-shaped parasitic element is implemented on the backside of the substrate as shown in the inside figure of Fig. 5. The length of the parasitic strip can be determined by quarter wave length at $5.5 \mathrm{GHz}$. The strip acts as a band stop filter to reject the specific band. Moreover, the notched frequency band is adaptable by varying the length and the location of the parasitic strip. Fig. 5 shows the VSWR of the proposed antenna after adding the parasitic strip. As observed from Fig. 5, a notched band at about 5.5 GHz for WLAN application is being created.

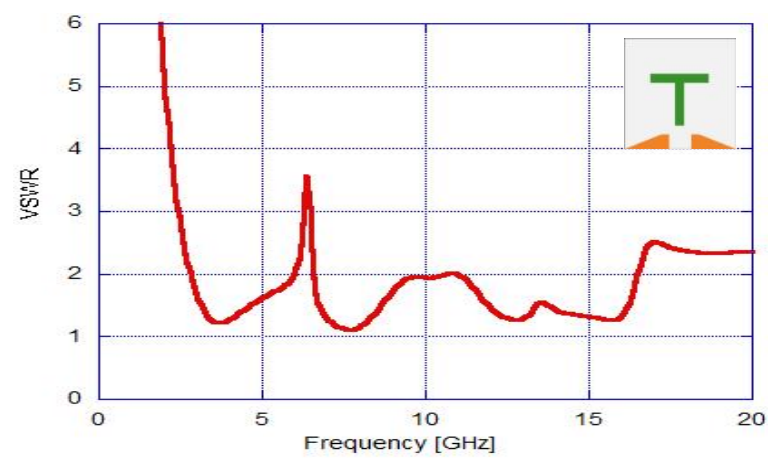

Figure 5: Simulated VSWR of the proposed antenna with the T-shaped parasitic strip.

The effect of the length of the vertical arm of the T-shape $\left(L_{5}\right)$ on the notched frequency is illustrated in Fig. 6, which presents the VSWR curves at different values of $L_{5}$. It is observed that this parameter has a major effect to allocate the notched frequency band. On contrast, the horizontal arm width has a very slight effect on the antenna performance.

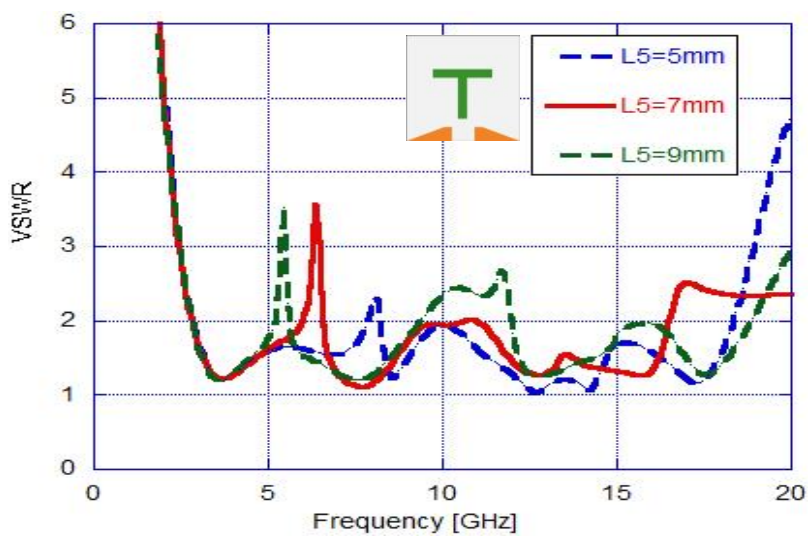

Figure 6: Simulated return loss and VSWR for different values $L_{5}$.

\section{Second Notched Band}

To create another notched-band at about $8.76 \mathrm{GHz}$ (from 8.15 to $9.61 \mathrm{GHz}$ ) an inverted $\Omega$-shaped slot is etched within the radiating patch. The simulated SWR of the dual band notched antenna is depicted in Fig. 7. By adjusting the different geometrical parameters of the $\Omega$-shaped slot the second notched band is achieved at the desired frequency.

The band-notched center frequency is given approximately by the expression [11]:

$$
\begin{gathered}
f_{\text {notch }}=\frac{c}{2 L_{T} \sqrt{\varepsilon_{e f f}}} \\
\varepsilon_{\text {eff }}=\frac{\varepsilon_{r}+1}{2}
\end{gathered}
$$

where $L_{\mathrm{T}}$ is the total horizontal broadens of the $\Omega$-shape, $\varepsilon_{e f f}$ is the effective dielectric constant, $\varepsilon_{r}$ is the dielectric constant of the substrate and, $c$ is the speed of the light.

Extensive simulations using 3D EM simulator are carried out to optimize the whole dimensions of the $\Omega$-shape as well as its position within the radiating patch to allocate the rejection frequencies at WiMAX range and at the WLAN frequency band applications.

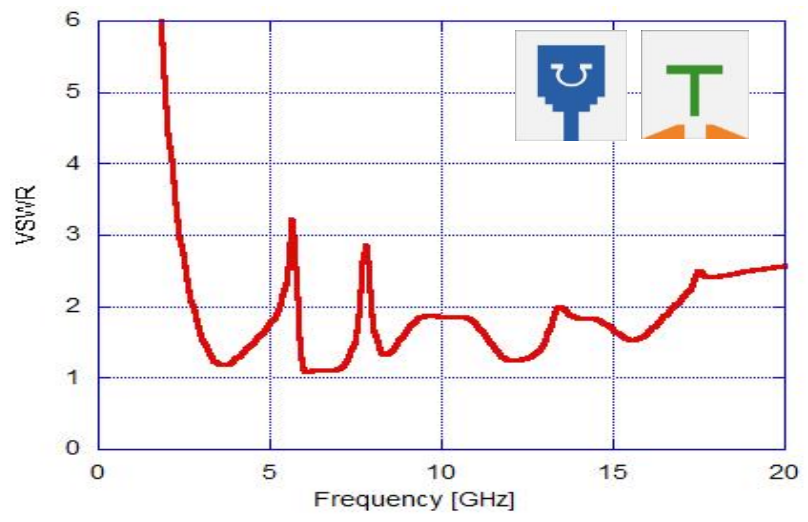

Figure 7: Simulated VSWR for the proposed dual band notched antenna. 


\section{Third Notched Band}

In order to create a third notched band over the frequency range of 3.1-3.6 GHz for WiMAX system, L-shaped slot is etched above the inverted $\Omega$-shaped slot within the radiating patch as shown in Fig. 8. By adjusting the main parameters; $L_{1}, L_{2}$, and $L_{3}$ of the slot, the desired rejected band is accomplished. The optimal values that perfectly allocate the three band notched frequency at the desired bands are tabulated in Table 1.

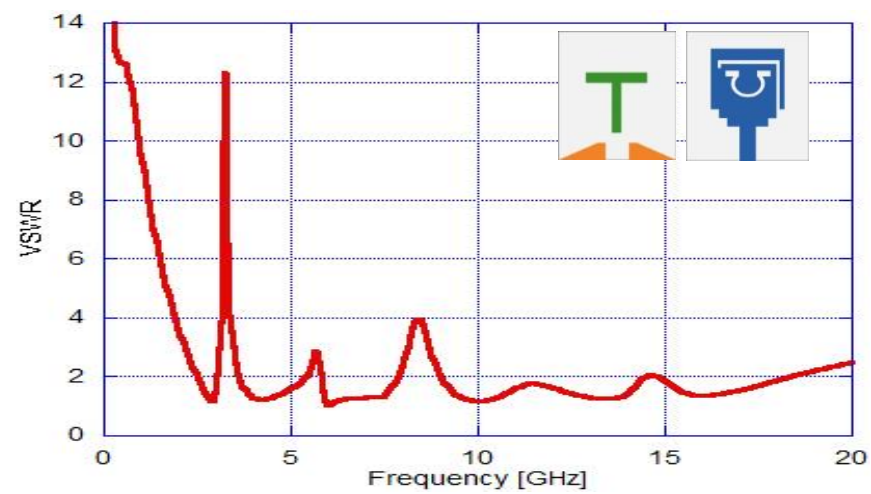

Figure 8: Simulated VSWR for the proposed triple band notched antenna.

\section{Results and Discussion}

To confirm the design concept, the UWB triple bandnotched antenna has been constructed and tested. The photograph of the prototype is shown in Fig. 9. The measured and simulated results for the return losses $\left(S_{11}\right)$ of the proposed antenna are shown in Fig. 10 (a). Fig. 10(b) shows the measured and simulated VSWR values of the fabricated antenna. The measured and simulated results using HFSS software are in good agreement. The measured results indicate a wide impedance bandwidth from 2.39 to more than $18 \mathrm{GHz}$, the triple notches are at $3,5.71$ and $8.76 \mathrm{GHz}$ covering the bandwidths from (2.69- $4.5 \mathrm{GHz}),(5.49-6.37$ $\mathrm{GHz}$ ) and (8.15-9.61 GHz), respectively. The inconsiderable dissimilarity between measurements and simulations may be due to some measurement or fabrication inaccuracies.

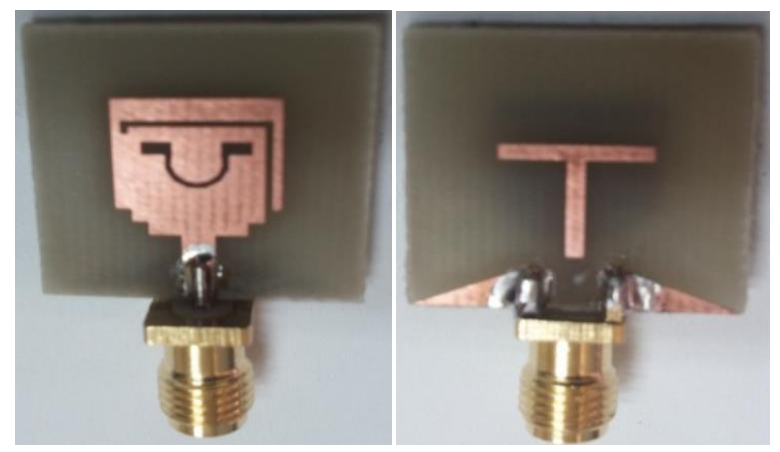

Figure 9: Photograph of the proposed fabricated tri-band notched UWB antenna.

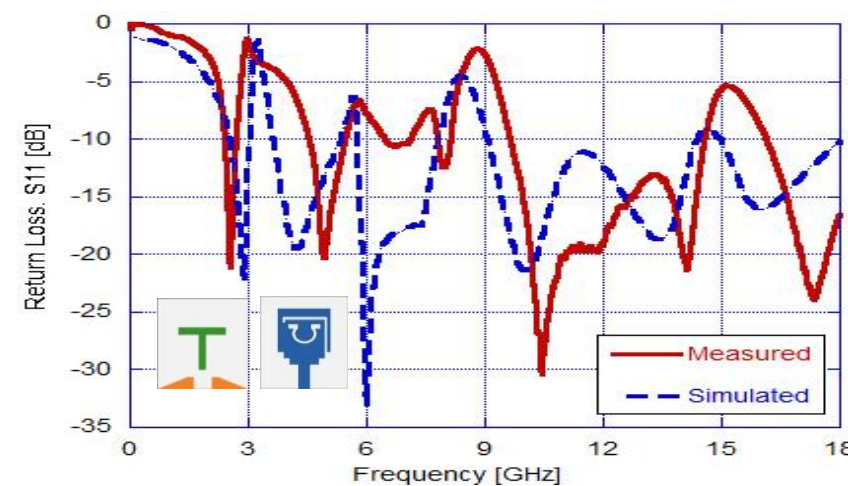

(a)

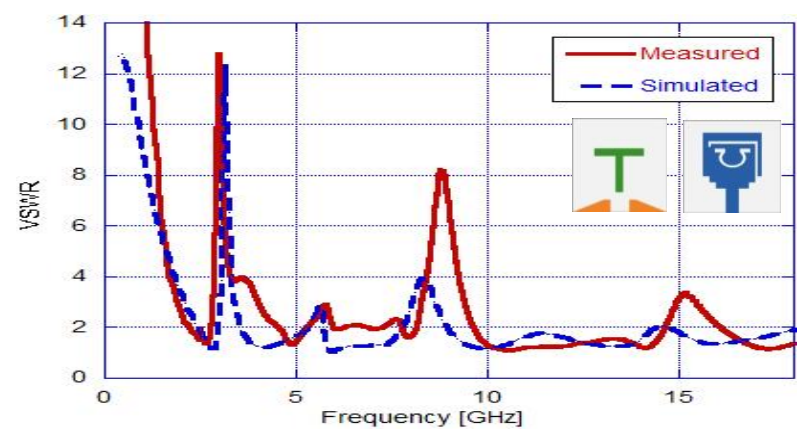

(b)

Figure 10: Measured and simulated (a) return loss, $S_{11}$ and (b) VSWR for the proposed triple band notched antenna.

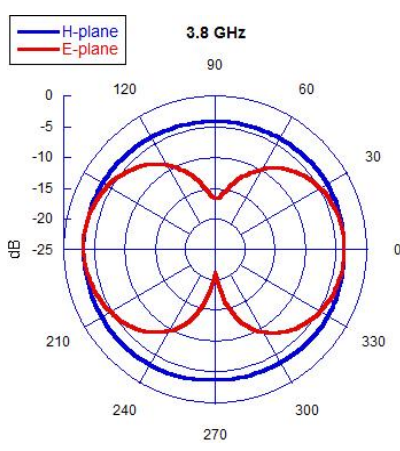

(a)

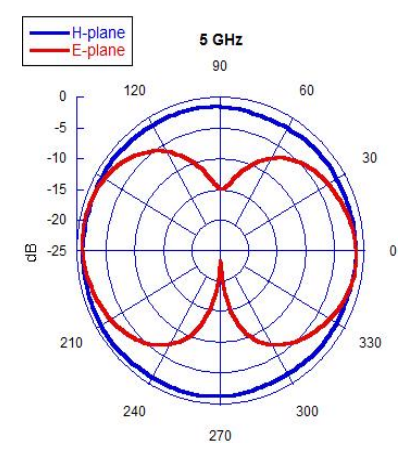

(b)

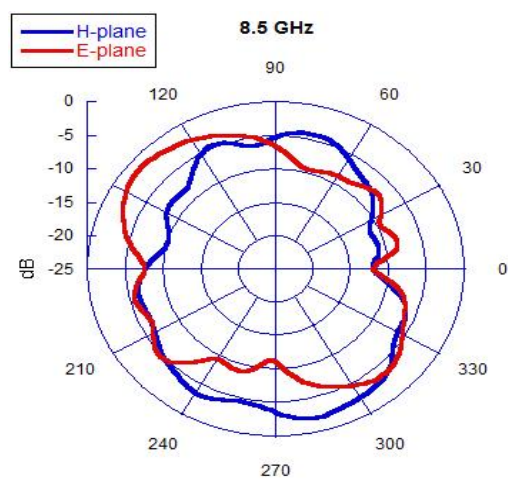

(c)

Figure 11: Simulated radiation patterns of the proposed antenna at (a) $3.8 \mathrm{GHz}$, (b) $5 \mathrm{GHz}$ and (c) $8.5 \mathrm{GHz}$. 


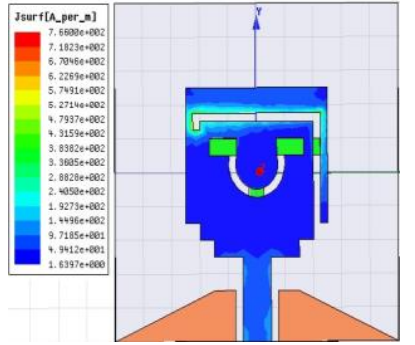

(a)

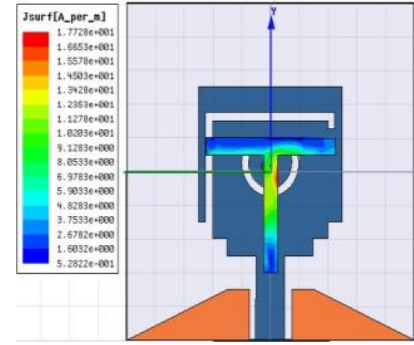

(b)

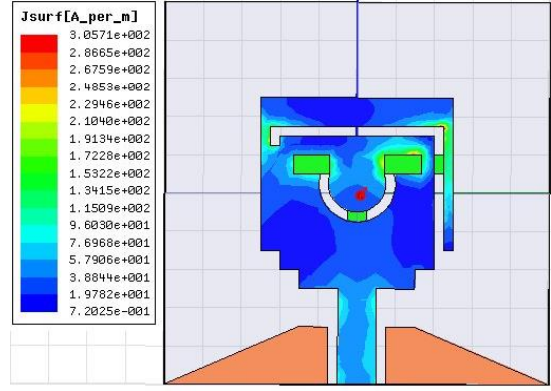

(c)

Figure 12: Simulated surface current distribution of the proposed antenna at (a) $3.3 \mathrm{GHz}$, (b) $5.6 \mathrm{GHz}$ and (c) 8 GHz.

The simulated far field radiation patterns of the proposed antenna at selective frequencies of $3.8,5$ and $8.5 \mathrm{GHz}$ are depicted in Fig. 11 (a), (b) and (c), respectively. It can be observed that, the proposed antenna pattern is displays good omnidirectional patterns in the H-plane and dipolelike radiation patterns in the E-plane at the passband frequencies (3.8 and $5 \mathrm{GHz}$ ). In contrast, the radiation pattern is deteriorates at the notched frequency $(8.5 \mathrm{GHz})$.

Figure 12 represents the current distributions of the proposed antenna at the three notched frequencies. As shown in Fig. 12 (a), (b) and (c), stronger current appears closes the edges of the L-, inverted $\Omega$ - and T-shaped stubs at the first, second, and third notched bands, respectively. The simulated total gain of the proposed antenna is shown in Fig. 13. It can be observed that the antenna displays acceptable gain uniformity except at the three notched bands where the gain falls down sharply, which denote the influence of the bandnotched feature of the proposed antenna. A table for the gain values at individual frequencies is demonstrated in Table 2 . The gain ranges from 3.35 to $8.7 \mathrm{dBi}$ over the whole band except at the three rejected bands, which verifies the proposed idea. The antenna gain at low frequencies is small but it is still acceptable regarding the wide-band achieved. The radiation efficiency is expected to be poor at low frequencies regarding the antenna dimensions and this also can be reflected by a low realized gain within the lower bands.

For comparing purpose, the performances of the presented antenna are compared to one presented in [22]. The $10 \mathrm{~dB}$ bandwidth of the presented antenna is extended from 2.39 to more than $18 \mathrm{GHz}$ except at the notched bands, while for the referenced one in [22] is extended from 3.8 to $10.6 \mathrm{GHz}$ except at the notched band. The gain in [22] seems to be more stable over the whole bandwidth than our design and this could be realized due to the huge extension of the bandwidth.

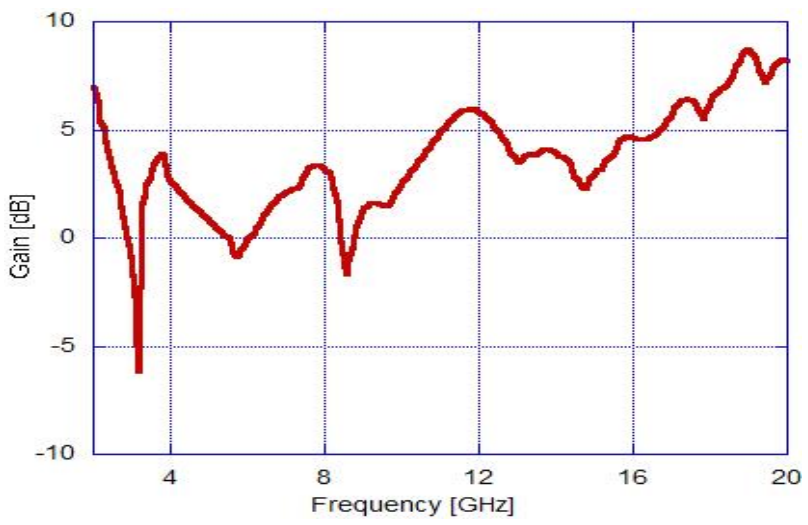

Figure 13: Simulated gain of the proposed antenna.

Table 2: The gain values at individual frequencies

\begin{tabular}{cc}
\hline Frequency $[\mathrm{GHz}]$ & Gain $[\mathrm{dB}]$ \\
\hline 2.4294 & 3.3558 \\
$\mathbf{3 . 1 6 1 5}$ (notched Freq.) & $\mathbf{- 6 . 1 4 0 6}$ \\
4.6258 & 1.4671 \\
$\mathbf{5 . 6 9 0 6}$ (notched Freq.) & $\mathbf{- 0 . 8 4 5 3 7}$ \\
7.7538 & 3.3779 \\
$\mathbf{8 . 6 1 9 1}$ (notched Freq.) & $\mathbf{- 0 . 9 8 4 1 9}$ \\
11.814 & 5.9747 \\
12.280 & 5.4135 \\
13.810 & 4.0955 \\
16.539 & 4.7529 \\
17.404 & 6.4580 \\
18.935 & 8.7170 \\
\hline
\end{tabular}

\section{Conclusion}

A microstrip-fed triple band-notched antenna for ultrawideband applications is proposed. The first notch at $3 \mathrm{GHz}$ is created by incorporating a T-shaped strip in the back side of the antenna, the second and third notches at 5.71 and $8.76 \mathrm{GHz}$ are created using slots of L-shaped and inverted $\Omega$-shaped etched on the radiating patch. The proposed antenna covers the bandwidth from $2.39 \mathrm{GHz}$ to greater than $18 \mathrm{GHz}$ with a standing voltage wave ratio of less than 2 except at the specified three notched bands. The total size of the proposed antenna is $20 \times 20 \times 1.6 \mathrm{~mm}^{3}$. The proposed antenna is realized on FR4 substrate of $\varepsilon_{r}=4.4$. The proposed antenna has a nearly omnidirectional radiation pattern. A respectable agreement between the measurement and simulation results are achieved. The compact size, simple structure, good performance and the measurements confirm that the proposed antenna is suitable for UWB applications with potentially reduce the frequency interference from several implicit technologies such as WLAN, WiMAX and X-band applications.

\section{References}

[1] Report and Order in the Commission's Rules Regarding Ultra-Wideband Transmission Systems, Released by Federal Communications Commission, 2002. 
[2] Yingsong Li, Wenxing Li1, Qiubo Ye and Raj Mittra, A Survey of Planar Ultra-Wideband Antenna Designs and Their Applications, Forum for Electromagnetic Research Methods and Application Technologies (FERMAT), 2014.

[3] J. A. Ansari, Kamakshi Kumari, Ashish Singh, Anurag Mishra, Ultra Wideband Co-planer Microstrip Patch Antenna for Wireless Applications, Wireless Personal Communication, 69, pp. 1365-1378, 2013.

[4] P. Kumar, J. L. Masa-Campos, Dual Polarized Monopole Patch Antennas for UWB Applications with Elimination of WLAN Signals, Advanced Electromagnetics, Vol. 5, No. 1, 2016.

[5] Ibrahim A.A., Safwat A.M.E, Microstrip-Fed Monopole Antennas Loaded With CRLH Unit Cells, IEEE Transactions on Antennas and Propagation, 60, Issue 9, 2012.

[6] S. H. Zainud-Deen, M. E. Badr, E. El-Deen, K. H. Awadalla, H. A. Sharshar, Microstrip Antenna with Defected Ground Plane Structure as a Sensor for Landmines Detection, Progress In Electromagnetics Research B, 27-39, 2008.

[7] Junhui Wang, Zedong Wang; Yingzeng Yin, Xianglong Liu, UWB Monopole Antenna with Triple BandNotched Characteristic Based on a Pair of Novel Resonators, Progress In Electromagnetics Research C, 49, 110, 2014.

[8] Awida M., Boutejdar A., Safwat A., El-Hennawy H., Omar A, Multi-Bandpass Filters Using Multi-Armed Open Loop Resonators with Direct Feed. IEEE/MTT-S Int. Microwave Symposium, Honolulu, HI, 2007.

[9] QiangWang, Yan Zhang, Design of a Compact UWB Antenna with Triple Band-Notched Characteristics. International Journal of Antennas and Propagation, Article ID 892765, 9 pages, 2014.

[10] Sai K. Venkata, Muktikanta Rana, Pritam S. Bakariya, Santanu Dwari, Manas Sarkar, Planar Ultrawideband Monopole Antenna with Tri-Notch Band Characteristics, Progress In Electromagnetics Research C, 46, 163170, 2014.

[11]Chao-ming Luo, Jing-Song Hong, Han Xiong, A TriBand-Notched UWB Antenna with Low Mutual Coupling Between The Band-Notched Structures, Radioengineering Journal, 22(4), 2013.

[12] Dang Trang Nguyen, Dong Hyun Lee, Hyun Chang Park, Very Compact Printed Triple Band-Notched UWB Antenna with Quarter-Wavelength Slots, IEEE Antennas and Wireless Propagation Letters, 11, 2012.

[13] Ehab K. I. Hamad and Mohamed A. Hassanien, Compact Patch Antenna Using Square-Slot CSRR for BandNotched UWB Application, 1st International Confer- ence on New Paradigms in Electronics \& Information Technologies (PEIT' 011), Alexandria, Egypt, 2011.

[14] Xian Ling Liang, Ultra-Wideband Antenna and Design, UltraWideband - Current Status and Future Trends, Chapter. 7, 2012.

[15] Chaozhu Zhang, Jing Zhang, Lin Li, Triple BandNotched UWB Antenna Based On SIR-DGS and ForkShaped Stubs. Electronics Letters, IET, 50, Issue 2., 2014

[16]Zhi-hong Tu, Wen-Ao Li, Qing-Xin Chu, Single-Layer Differential CPW-Fed Notch-Band Tapered-Slot UWB Antenna, IEEE Antennas and Wireless Propagation Letters, 13, 2014.

[17] Fuguo Zhu, Gao S., Ho A.T.S., Abd-Alhameed R.A., See C.H., Brown T.W.C., Jianzhou Li, Gao Wei, Jiadong $\mathrm{Xu}$, Multiple Band-Notched UWB Antenna with Band-Rejected Elements Integrated in the Feed Line, IEEE Transactions on Antennas and Propagation, 61, Issue 8, 2013.

[18] Yongfan Lin, Jiangang Liang, Zimu Yang, Zhiyong Xu, Rui Wu, A Novel UWB Antenna with Dual-band Notched Characteristics, Progress In Electromagnetics Research Symposium Proceedings, Guangzhou, China, Aug. 25-28, 2014.

[19] Maiti S., Pani N., Mukherjee A, Modal analysis and design a planar elliptical shaped UWB antenna with triple band notch characteristics, Signal Propagation and Computer Technology (ICSPCT) conference, 2014.

[20] Pritam S. Bakariya, Santanu Dwari, Manas Sarkar, Triple Band Notch UWB Printed Monopole Antenna with Enhanced Bandwidth, AEU - International Journal of Electronics and Communications, 69, Issue 1, 26-30, 2015.

[21]Tapan Mandal, Santanu Das, UWB Printed Plaque Monopole Antennas for Tri-Band Rejection, Microwave and Optical Technology Letters, 55, Issue 3, 674-680, 2013.

[22] Tan-Phu Vuong, Anthony Ghiotto, Yvan Duroc, Smail Tedjini, Design and characteristics of a small U-slotted planar antenna for IR-UWB, Microwave and Optical Technology Letters, Vol. 49, No. 7, pp. 17271731, 2007. 